\title{
Technological Fix: Students in Mobile Phone Repairs
}

\author{
Mark Ofori Nketia \\ Ghana Communication \\ Technology University \\ Tesano, Accra
}

\author{
Prince Obeng Lokko \\ Ghana Communication \\ Technology University \\ Tesano,Accra
}

\author{
Eric Adu-Gyamfi \\ Ghana Communication \\ Technology University \\ Tesano, Accra
}

\begin{abstract}
The digital world is still evolving with many opportunities and challenges. The mobile phone is one of the devices that has transformed the telecommunication industry. Repair of mobile phones places itself within the idea of circular economy in an urban setting, and the allied process like refurbishing, reengineering, and recycling are advantageous to the environment, contributing to sustainable development goals. This study sought to access the performance and skill gained by some students in selected second cycle institutions in Southern Ghana who undergone training to technologically fix mobile phones. The study found out that about $90 \%$ of the students were able to install, uninstall and repair mobile systems as well as becoming conversant with the use of various tools $\&$ instruments in mobile phone repairing.
\end{abstract}

\section{Keywords}

Telecommunication, Mobile phone, Technology, Women, students.

\section{INTRODUCTION}

Mobile technology has become one of the fastest growing technologies in the world. Today people use mobile phones to stay in touch with friends and family, to share stories and photographs in social media, and to carry out financial transactions. Ownership of mobile phones has been shown to be an important tool to empower women. In almost one third of the economies for which data are available (31 out of 69), women's mobile phone ownership is close to parity with that of men. In 12 of these 69 economies, the proportion of women owning a mobile phone is larger than the proportion of men, while there are 26 countries for which male mobile phone ownership is substantially higher than that of women [3]. A report made by DATAREPORTAL shows that there were 41.69 million mobile connections in Ghana in January 2021[4]. The number of mobile connections in Ghana increased by 3.1 million $(+8.1 \%)$ between January 2020 and January 2021. The number of mobile connections in Ghana in January 2021 was equivalent to $132.8 \%$ of the total population [4]. Mobile phone technology has contributed tremendously in transforming the financial sector. As of January 2021, 38.9 percent of the population aged 15 years and older had a mobile money account in Ghana. The share of mobile money users increased over the previous three years [3].

Practices of technology repair in developing country contexts play crucial and often overlooked roles in supporting the Sustainable Development Goals 9 which is Investing in ICT access and quality education to promote lasting peace [7]. Repair of mobile phones places itself within the idea of circular economy in an urban setting, and the allied process like refurbishing, reengineering, and recycling are advantageous to the environment contributing to sustainable development goals [1] [7]. According to Omofonmwan and Chukwuedo [5]. The functionality of electronic products is not eternal and without breakdown. These circuits can breakdown through one or more of their components, hence the need for maintenance and repairs of these products when there is breakdown.

The current situation whereby people venture into electronic installation, repair and servicing because they do not get their preferred job needs serious attention. It is obvious to be a contributing factor in why repaired phones do not last longer. Moreover, women have achieved parity with men more than ever before in education and in their places of work. The progress made by women involving the retention and recruitment of in the fields of science, technology, engineering electronics and mathematics is still comparatively insignificant to men. The struggle for equality is an on-going process that continues to make advances in Ghana where women have been socialized to accept certain trades as the preserve of men. A review of the membership of the Ghana Electrical Contractors Association [2] indicates that out of a total of 1,157members, there was only one (1) female nation-wide. It is therefore not surprising that a majority of electrical appliances continue to be repaired, installed and serviced by men who have been socialized in Ghana to dominate this profession. Empowering young students in Mobile phone repairs will not only enhance their knowledge and skills but give them a source of livelihood.

\section{OBJECTIVE}

- To promote young students in the installation and servicing of Mobile Phones.

- To equip trainees with the capacity to train others on mobile phones repairs.

\section{METHODOLOGY}

The training, involved 78 participants in 3 secondary cycle institutions across Southern Ghana. Participants were divided into 13 groups for the practical training session. The three instructors also had one group for the practical session. Each group was allocated a work station. A pre-training assessment was conducted to assess the students' prior knowledge levels in electronics and mobile phone repairs as well as their mode of learning. From these learning compositions mode, the trainers took them through the theory aspects of mobile phone repairs and maintenance before taking them through the practical aspects. They were allowed to ask questions on any aspect they lacked initial understanding for clarifications to clear their doubts. The training methods will be a blend of theory $(30 \%)$ and practical $(70 \%)$ to yield the stated objectives over the training period. When the practical training was done, a span of 30minutes is allocated for them to have group discussions. Emphasis was given to the practical classes especially on the application of standards. Every participant was provided with the printed training manual of Mobile phone applications and systems installation, which helped each participant for better understanding of the 
deliberations during the training and also has become an asset and source of reference for future consultation purposes. After the training questionnaires were given out to participants to access their performance.

\section{TRAINING}

\subsection{Identifying Parts and Components}

Participants were made to learn how to identify parts and components on the Printed Circuit Board (PCB) of a mobile cell phone. Identification of these parts and components is not that difficult. The PCB of any mobile phone of any brand namely Nokia, Samsung, Motorola, China Mobile Phones etc is divided into 2 Parts namely: (1) Network Section; and (2) Power Section. When identifying parts, electronic components and ICs on the PCB of a mobile cell phone, it is important to keep these two sections in mind.

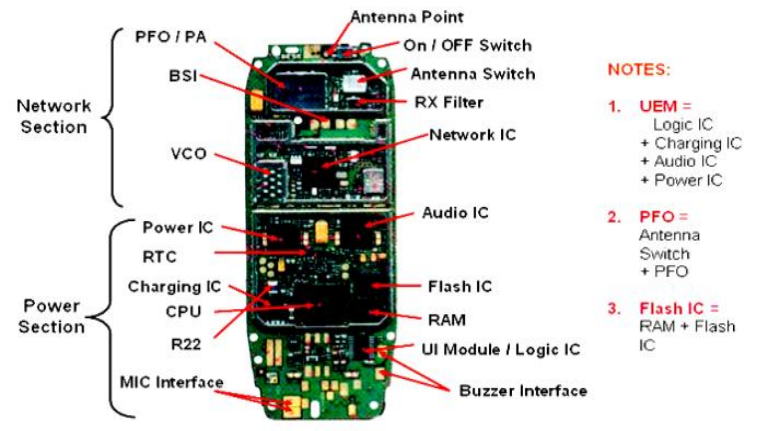

Fig 1: PCB diagram of a mobile phone[10]

\subsection{Explicit Knowledge}

Through explicit knowledge, students were mainly made to understand the conceptual knowledge on how to repair spoilt gadgets. This includes information about the different parts of the phone, how they are connected with each other parts, and the functional connections (including discrete paths in the circuitry) that link them into an operational hole, and the larger schematic similarities and differences that unite or separate different phone models. Students were also taught in GSM Mobile Phone Troubleshooting, CDMA Mobile Phone Troubleshooting and Practically handset repairing.

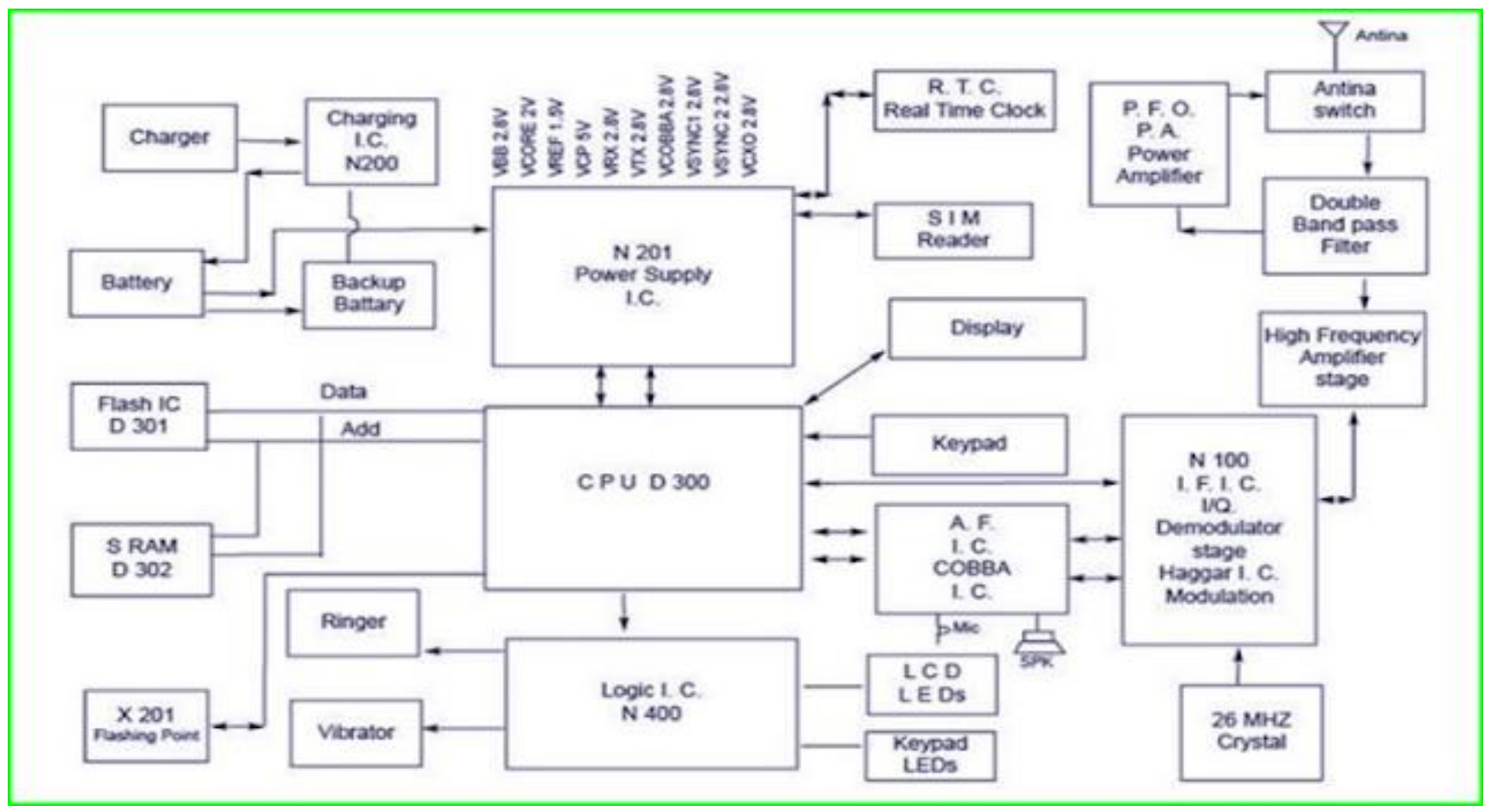

Fig 2: Schematic Diagram of Nokia 3310

\section{ANALYSIS AND DISCUSSION}

\subsection{Prior Knowledge Level in Mobile Phone Repairs and Maintenance for Students}

As depicted in table 1 and figure 3, (66.7\%) of the students who partook in the training had no knowledge on mobile phone repairs and maintenance systems prior to the training, whiles (33.3\%) of them had some basic to average knowledge on phone repairs and maintenance systems.
Table 1: Prior Knowledge

\begin{tabular}{|c|c|c|c|c|c|}
\hline & & Frequency & Percent & $\begin{array}{l}\text { Valid } \\
\text { Percent }\end{array}$ & $\begin{array}{c}\text { Cumulative } \\
\text { Percent }\end{array}$ \\
\hline \multirow{4}{*}{ Valid } & $\begin{array}{c}\text { No } \\
\text { Knowledge }\end{array}$ & 52 & 66.7 & 66.7 & 66.7 \\
\hline & Basic & 14 & 17.9 & 17.9 & 84.6 \\
\hline & Average & 12 & 15.4 & 15.4 & 100.0 \\
\hline & Total & 78 & 100.0 & 100.0 & \\
\hline
\end{tabular}




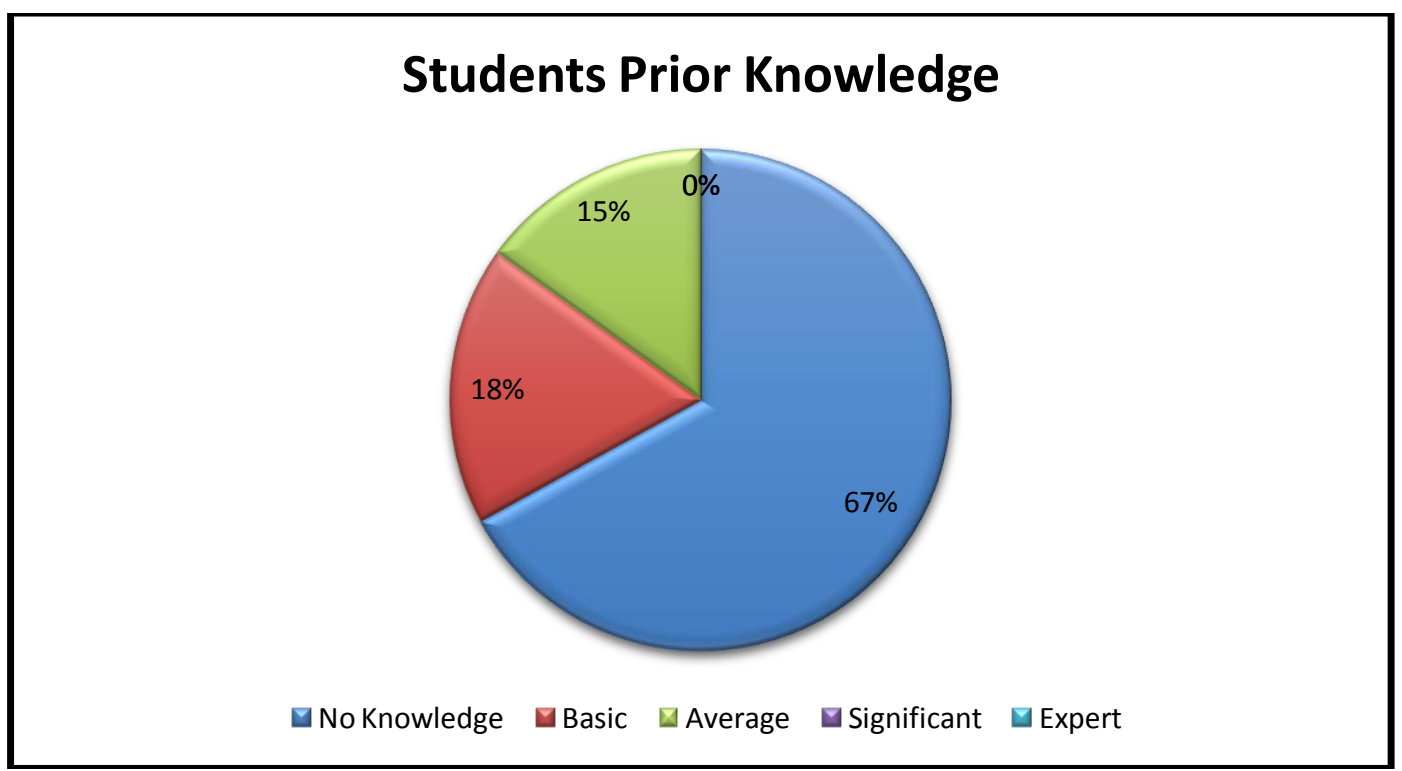

Fig 3: Prior Knowledge in Mobile Phone Repairs and Maintenance for Students

5.2 Prior Knowledge Level in Mobile Phone Repairs and Maintenance for Instructors

There were 3 instructors who took part in this study. Table 2 gives a descriptive analysis of their knowledge level in mobile phone repairs and maintenance prior to the training. Figure 4 gives a pictorial view of their knowledge level. It was observed that $33.3 \%$ of the instructors had no knowledge in mobile phone repairs and maintenance while another $33.3 \%$ had average knowledge with $33.3 \%$ also having significant knowledge in the subject area.

Table 2: Instructors Prior Knowledge

\begin{tabular}{|ll|r|r|r|r|}
\hline & & & & \\
& & Frequency & Percent & Valid Percent & Cumulative Percent \\
\hline Valid & No Knowledge & 1 & 33.3 & 33.3 & 33.3 \\
& Average & 1 & 33.3 & 33.3 & 66.6 \\
& Significant & 1 & 33.3 & 33.3 & 100.0 \\
& & 3 & 100.0 & 100.0 & \\
\hline
\end{tabular}

\section{INSTRUCTORS PRIOR KNOWLEDGE}

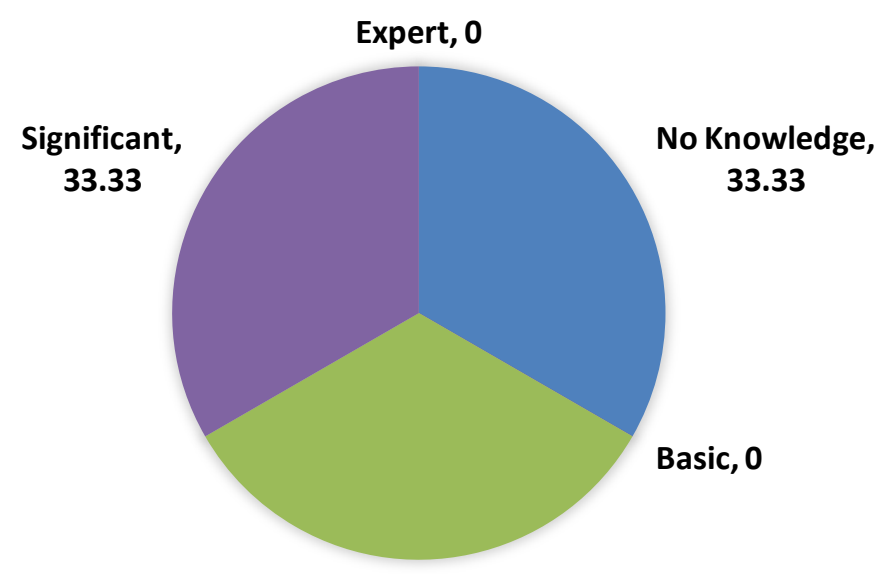

Average, 33.33

Fig 4: Prior Knowledge in Mobile Phone Repairs and Maintenance for Instructors 
repairs, the consultant saw the need to organize the training program in a way that will benefit the participants. This includes the use of simple illustrations during the training where possible, and the use of group discussions to help participants share their understanding on the subject matter with each another. All this amongst others, helped to make the training program successful.

\subsection{Post Training Survey}

In order to ascertain the outcome of the training and help improve the quality of the training in subsequent schools, the consultant undertook the survey in a form of a questionnaire. The areas covered by the survey includes (but not limited to) trainees' ability to repair and provide maintenance for a mobile phone (before and after the training), and the desire to increase their knowledge on mobile phone repairs and maintenance systems.

\subsection{Students Ability to Repair Mobile Phone}

As depicted in figure 5 above, before the training, more than $26(33.3 \%)$ of the participants had no confidence in their ability to repair and maintain a mobile phone. However, they became more self-confident, encouraged and motivated after the training. 75 trainees representing $96 \%$ of the trainees who were confident that they could repair and maintain a mobile phone device on their own.

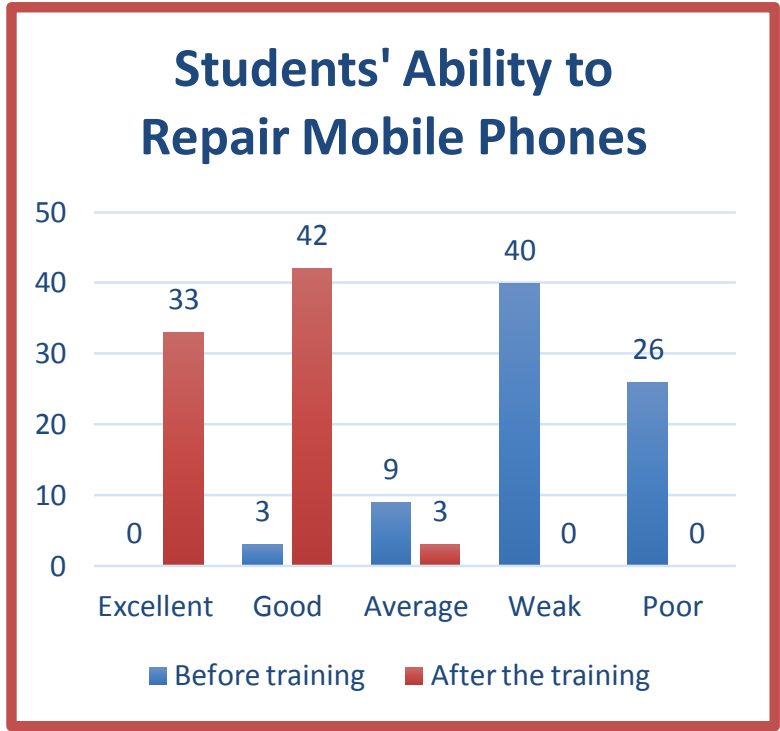

Fig 5: Students Ability to repair mobile phone

\subsection{Participants desire to increase their knowledge on mobile phone repairs $\&$ maintenance application systems}

Almost all of the participants expressed interest in furthering their training on mobile phone repairs and maintenance application systems. As depicted in the chart below, more than $97 \%$ of the participants expressed a great interest to increase their knowledge in repairs of mobile phones in the near future.

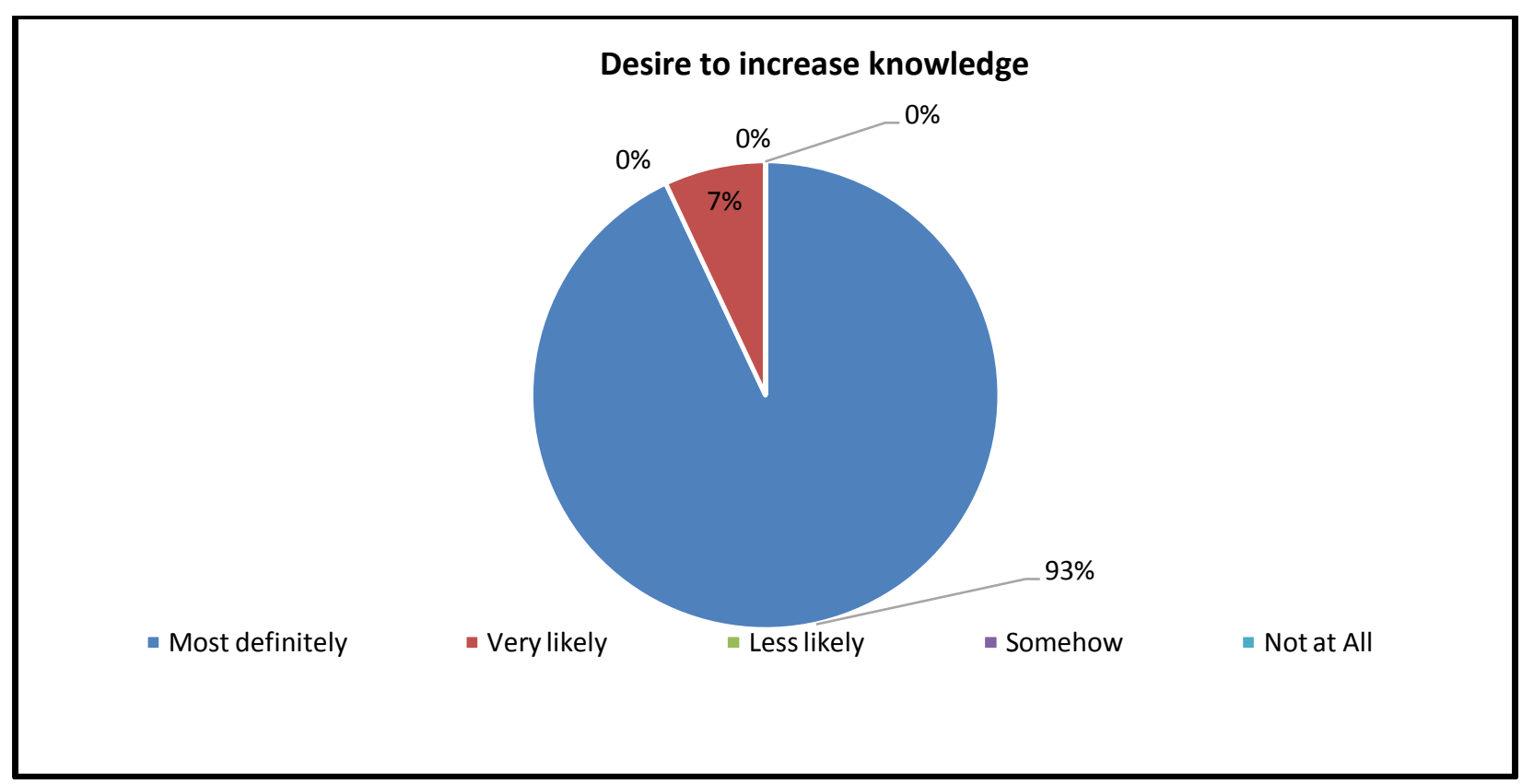

Fig 6: Participants desire to increase their knowledge on mobile phone repairs and maintenance application systems

\section{CONCLUSION}

Businesses and industries around the world are beginning to value skills in over academic qualifications. It is therefore prudent that student get the rightful skills in addition to their academic education. This study shows that the students were able to install, uninstall and repair mobile systems as well as becoming conversant with the use of various tools \& instruments in mobile phone repairing. With increasing smartphone penetration and the short lifecycle of phones, the repair economy has emerged as a potential niche for customized innovations and employment generation.

\section{REFERENCES}

[1] Anjana, N R. 2020. Enskilment of Smartphone Technicians: An Anthropological Inquiry on technicians of Ritchie Street, Chennai. International Journal of Scientific \& Technology Research Volume 9, Issue 03, March 2020 ISSN 2277-8616 5984 IJSTR@2020 
WwW.ijstr.org

[2] Ghana Electrical Contractors Association (GECA) Report, 2018

[3] ITU 2021. Measuring digital development Facts and figures 2020. International Telecommunication Union publication. Retrieved 28 April 2021, from https://www.itu.int/en/ITU-

D/Statistics/Documents/facts/FactsFigures2020.pdf.

[4] Kemp, S. 2021. Digital in Ghana: All the Statistics You Need in 2021 - DataReportal - Global Digital Insights. Retrieved 28 April 2021, from https://datareportal.com/reports/digital-2021-ghana.

[5] Omofonmwan, G.O., and Chukwuedo, S.O 2013. Information and communication technology: The pivot of teaching and learning of skills in electrical and electronics technology programme in Nigeria.

[6] International Journal of Vocational and Technical Education. Vol. 5(6), pp. $117-123$.
[7] Sasu, D, D. 2021. Ghana: mobile money accounts 20182021 Statista. Statista. Retrieved 28 April 2021, from https://www.statista.com/statistics/1175988/mobilemoney-accounts-ghana/

[8] Türkeli, S., Huang, B., Stasik, A., \& Kemp, R. 2019. Circular Economy as a Glocal Business Activity: Mobile Phone Repair in the Netherlands, Poland and China. Energies, 12(3), 498. https://doi.org/10.3390/en12030498

[9] United Nations 2017. Sustainable Development Goals. Accessed from https://www.un.org /sustainabledevelopment/blog/2017/06/sustainabledevelopment-goal-9-investing-in-ict-access-and-qualityeducation-to-promote-lasting-peace/.

[10] Santosh. D, 2021. "Mobile Phone Sections and Components / IC Parts in Section \& Function", Mobile Phone Repairing, 2021. [Online]. Available: http://www.mobilecellphonerepairing.com/sectionsparts-inside-a-mobile-cell-phone.html. [Accessed: 14 March- 2021]. 